\title{
Cosmetic bio-product based on cinnamon essential oil "Cinnamomum verum" for the treatment of mycoses: preparation, chemical analysis and antimicrobial activity
}

\begin{abstract}
The evolution of cosmetology is, in recent years, considerable, especially by the number of new substances that appear particularly natural substances. Hence, this paper presents the physicochemical analyzes and the biological activities of a cosmetic formulation based on the essential oil of Cinnamomum verum (bark of cinnamon). The first part of the work, and after the extraction of the essential oil of cinnamon by hydrodistillation, we analyzed all the constituents of this oil by GC-MS. The results of these analyzes showed that the main composition consists of three compounds: cinnamaldehyde (89.31\%), cinnamyl acetate $(2.44 \%)$, linalool $(1.60 \%)$. the last part of this work aimed to investigate the antimicrobial activities in cinnamon essential oil by assessing each against mycotic microbes, then the antibacterial activity was done against: Escherichia coli, Pseudomonas aeruginosa and Staphylococcus aureus, and Antifungal activity was done against yeast Candida albicans and Aspergillus niger. The data of these microbial activities have shown remarkable activity, which implies the use of this oil in the treatment of mycoses.
\end{abstract}

Keywords: cinnamomum verum, essential oil, GC-MS, antimicrobial activity, cosmetic product, Mycoses
Volume 5 Issue I - 2019

\author{
Tarik Ainane,' Fatima Khammour, ${ }^{2}$ Nawal \\ Merghoub, ${ }^{3}$ Meriem Elabboubi, ${ }^{2}$ Sanaa \\ Charaf, ${ }^{2}$ Ayoub Ainane, ${ }^{2}$ M'hamed Elkouali, ${ }^{2}$ \\ Mohammed Talbi, ${ }^{2}$ El Hassan Abba,' Sanaa \\ Cherroud' \\ 'Superior School of Technology-Khenifra (EST-Khenifra), \\ University of Moulay Ismail, Morocco \\ 2Laboratory of Analytical Chemistry and Physical Chemistry of \\ Materials, University of Hassan II, Morocco \\ ${ }^{3}$ Green Biotechnology Center, Morocco
}

Correspondence: Tarik Ainane, Superior School of Technology - Khenifra (EST-Khenifra), University of Moulay Ismail, PB I70, Khenifra 54000, Morocco, Email ainane@gmail.com

Received: May 24, 2018 | Published: January 09, 2019

\section{Introduction}

The history of humanity seems inseparable from cosmetics. From time immemorial, they have been allies of women and, often, of men. Over time, habits and habits have of course been very different, but cosmetics have always been present. ${ }^{1-3}$

The evolution of cosmetology is, in recent years, considerable, especially by the number of new substances and new formulations that appear and by the pressure of increasingly stronger regulations. The cosmetic product is no longer that product that owed everything to the artificial, the false-semblant in order to give the illusion of a reality or rather to hide this reality. Cosmetology has become a science, based on precise facts of a biological and physicochemical nature, and this new conception has definitely been imposed. ${ }^{4-8}$

In recent years, the cosmetics market has been growing, evolving and becoming more and more competitive. The formulations always push the boundaries of chemistry and galenics further to discover, every day, new presentations. This is why cosmetic products are becoming more specific, more effective and more targeted.

This evolution is to be compared with the changes in consumption of the cosmetic product in recent decades. The use of these products is growing, and every consumer uses many different cosmetics throughout the day. ${ }^{9,10}$

On the other hand, the industrial development of natural resources in Morocco was begun for ten years, while several industries were installed to produce Bio-products and exploit these resources, because Morocco is undoubtedly both a well-known name and a significant producer in the world of natural product particularly essential oils. This is the result of several main factors: The geography and climate, which is governed by the Mediterranean Sea, the Atlantic Ocean, the desert in the south and its three main mountain ranges. Morocco hosts a complete range of Mediterranean climates and soils that favour an extremely rich biodiversity, including an impressive variety of aromatic plants (both Mediterranean classics and endemic species). Also, the essential oils are the subject of intensive scientific research and attract attention of cosmetic and pharmaceutical industries due to their potential as active pharmacological compounds or natural preservatives. Enormous diversity of this group of natural compounds and wide spectrum of biological properties make them attractive for many industries. Regardless from sensory properties of essential oils, antimicrobial and antifungal activities are the goal of research. ${ }^{11-15}$

The objective of this manuscript is to give a chemical and biological study on the essential oil of Cinnamomum verum, which is of industrial interest in cosmetic preparations. More precisely, this work is based on the identification of the chemical compounds of this essential oil by gas chromatography coupled with mass spectrophotometry GC-MS and the carrying out of antimicrobial activities by antibacterial tests against Escherichia coli, Pseudomonas aeruginosa and Staphylococcus aureus and antifungal tests against Candida albicans and Aspergillus niger.

\section{Material and methods}

\section{Plant material: Extraction and analysis of essentials oils}

Bark of the plant Cinnamomum verum were purchased from the local market in Khénifra (Morocco), and identified at Department of Environmental engineering (EST-Khenifra-Moulay Ismail University). Voucher specimen of the plants were dried and deposited at the herbarium of laboratory. After this step, dried plant was submitted to steam distillation in a Clevenger-type apparatus for $3 \mathrm{~h}$ and essential oil obtained were separated from water and dried over anhydrous $\mathrm{Na} 2 \mathrm{SO} 4$ then stored at $4{ }^{\circ} \mathrm{C}$ until use. 
Analysis of essential oils is done by gas chromatography coupled to mass spectrometry GC-MS (Hewlett Packard 5971A). Determining the relative proportions of various molecules is obtained by gas chromatography coupled with flame ionization (GC-FID). Analysis by GC-MS and GC-FID are made under identical conditions. GCMS was performed on a DB-5 column (5\% phenyl methyl siloxane) whose dimensions are: length: $30 \mathrm{~m}$; diameter: $250 \mu \mathrm{m}$; film thickness 0.32 microns. The applied temperature program was $40^{\circ} \mathrm{C}$ for $5 \mathrm{~min}$, 40 to $200^{\circ} \mathrm{C}$ at $3^{\circ} \mathrm{C} / \mathrm{min}$ then held at $200^{\circ} \mathrm{C}$ for $5 \mathrm{~min}$. The carrier gas was helium (pressure: $49.9 \mathrm{kPa}$, flows: $1 \mathrm{~mL} / \mathrm{min}$ ). The source of the mass spectrometer to a temperature of $230^{\circ} \mathrm{C}$ and the mass range is scanned from 50 to $350 \mathrm{amu}$. Identification of the components was based two processes. First method: on the comparison of their GC retention indices (RI) on non polar and polar columns, determined relative to the retention time of a series of n-alkanes with linear interpolation, with those of authentic compounds or literature data. And second method on computer matching with commercial mass spectral libraries and comparison of spectra with those of our personal library. Relative amounts of individual components were calculated on the basis of their GC peak areas on the two capillary Rtx-1 and RtxWax columns, without FID response factor correction. . $^{11,12,16,17}$

\section{Antimicrobial activity evaluation}

The essential oil of Cinnamomum verum was tested against five microorganisms, including two Gram-negative bacteria: Escherichia coli, Pseudomonas aeruginosa, one Gram-positive bacterium, Staphylococcus aureus, the yeast Candida albicans and the mold Aspergillus niger. Spores of the mold were harvested into sterile distilled water from monoconidial cultures, developed on potato dextrose at $24^{\circ} \mathrm{C}$ during 7 days. The minimum inhibitory concentrations (MICs) of the essential oil were determined against all the tested microorganisms using the broth microdilution method. ${ }^{18-20}$ Microbial samples were prepared by dilution with growth media to obtain inocula at 105 colony forming units (CFU) per $\mathrm{mL}$ culture. The test cultures were performed in Muller Hinton broth for bacteria, or in Sabouraud dextrose broth for Candida albicans or Aspergillus Niger. The culturing media were supplemented with $0.5 \%$ Tween- 20 . Samples of the essential oil were prepared by different dilutions in $\mathrm{DMSO}$, and tested at a final concentration ranging from 0.5 to $5 \mu \mathrm{g}$ oils per $\mathrm{mL}$ culture. Microbial growth was allowed in 96-well microtitration plates by dispensing into each well $180 \mu \mathrm{L}$ of microbial culture and $20 \mu \mathrm{L}$ of essential oil sample at various concentrations. The final DMSO amount, being less than $4 \%$, was without growth inhibition effect. Sample blanks were prepared for all the extracts by adding $20 \mu \mathrm{L}$ of essential oil sample to $180 \mu \mathrm{L}$ of Mueller Hinton (or Sabouraud dextrose) broth medium. The plates were incubated at $37^{\circ} \mathrm{C}, 24 \mathrm{~h}$ for the bacteria and $48 \mathrm{~h}$ for Candida albicans or Aspergillus Niger. The antibiotics, tetracycline and pinicilin were used as positive controls against the bacteria and chloramphenicol and amphotericin B for Candida albicans and Aspergillus Niger, respectively. The viability of the examined microorganisms was assessed by measuring absorbance of cultures at $600 \mathrm{~nm}$ against the Mueller Hinton or the Sabouraud dextrose broth, using a Multiscan Spectrophotometer (Thermo-Fisher Scientific Spectrophotometer). Tests were carried out in triplicate, and repeated twice. Microbial growth inhibition was expressed in percentage term according to the equation:

$$
\% \text { Inhibition }=\left[1-\left(\frac{A_{\text {sample }}-A_{\text {sample blank }}}{A_{\text {control }}}\right)\right] \times 100
$$

i. Asample: absorbance of the culture test sample; ii. Asample blank: absorbance of the extract sample in the nutrient broth;

iii. Acontrol: absorbance of the cullture control.

\section{Results and discussion}

In a survey conducted on the treatment of mycoses, patients are less and less confident in their drug treatments. They wish more and more to know everything about what they will consume, but also turn more easily on natural formulations sold in herbalists, indeed, More than $80 \%$ of Moroccans trust in herbal medicine. Essential oils, secreted naturally by plants, to protect it, or to make it attractive, for example, perfectly meet their expectations: the fields of use are varied, the products sold in cosmetology are random, and the cost, which depends of the composition, is not excessive. In the second survey, we conducted a study of dozens of cosmetics in different regions of Morocco, so most of these products are formulations based on plant extracts, especially the essential oil of the cinnamon plant. So this study was performed in order to evaluate the antimicrobial properties of an essential oil of Cinnamomum verum bark on responsible strains of mycoses.

Essential oil Table 1 shows the chemical composition of the essential oil of Cinnamomum verum bark. The composition of the essential oil of Cinnamomum verum is quite variable, depending on the locality of growth and the organ used. However, many paper report eugenol as the main component of the oil of the leaves and cinnamaldehyde for the oil from the bark. ${ }^{21-25}$ This is in agreement with the sample used in this study (cinnamaldehyde $=89.31 \%$ ), other important constituents present in interesting concentration were cinnamyl acetate $(2.44 \%)$ and linalool (1.6\%).

Table I Constituents identified in the oils of Cinnamomum verum (Bark)

\begin{tabular}{|c|c|c|}
\hline Pic & Compound & $\%$ \\
\hline 1 & $\alpha$-pinene & 0.37 \\
\hline 2 & camphene & 0.12 \\
\hline 3 & benzaldehyde & 0.24 \\
\hline 4 & $\beta$-pinene & 0.15 \\
\hline 5 & myrcene & 0.05 \\
\hline 6 & $\alpha$-phellandrene & 0.01 \\
\hline 7 & $\alpha$-terpinene & 0.03 \\
\hline 8 & p-cymene & 0.02 \\
\hline 9 & $\beta$-phellandrene & 0.23 \\
\hline 10 & linalool & 1.60 \\
\hline 11 & 2-ethenyl-3-methyl phenol & 0.01 \\
\hline 12 & borneol & 0.01 \\
\hline 13 & terpinen-4-ol & 0.02 \\
\hline 14 & $\alpha$-terpineol & 0.01 \\
\hline 15 & cinnamaldehyde & 89.31 \\
\hline 16 & $\delta$-elemene & 0.33 \\
\hline 17 & $\alpha$-cubebene & 0.12 \\
\hline 18 & eugenol & 0.39 \\
\hline 19 & ethyl 3-phenyl-propan-1-ol & 0.05 \\
\hline 20 & cinnamyl acetate & 2.44 \\
\hline 21 & $\alpha$-humulene & 0.01 \\
\hline 22 & $\delta$-cadinene & 0.01 \\
\hline 23 & bicyclogermacrene & 0.01 \\
\hline 24 & benzyl benzoate & 0.01 \\
\hline
\end{tabular}


The antimicrobial activity of the essential oil was investigated against 3 bacteria and 2 fungi species, using MIC methods. The essential oil showed strong antimicrobial activity against all microorganisms tested including three bacteria and two fungi species as shown in Table 2. It was highly effective against Gram positive bacteria Staphylococcus aureus, and Gram negative bacteria Escherichia coli and Pseudomonas aeruginosa.

Widespread studies have demonstrated the effectiveness of natural products such as plant essential oils to reduce the damages of bacteria and fungi responsible of mycosis. Their research recommended application of plant essential oils as a good alternative to chemical treatments. Our results indicated acceptable antimicrobial activity of Cinnamomum verum essential oil. To the best of our knowledge,

Table 2 Antimicrobial activities of Cinnamomum verum Essential oil the antimycotics activity of Cinnamomum verum against pathogenic bacteria and fungi has never been reported, but several previous works were studied the activity of this oil on the same strains, that is to say that the medical application was not made. ${ }^{26-30}$ Several factors, such as chemical structure, active biological compound, concentration of essential oils and type of microorganisms play important roles in the efficiency of essential oils. The GC-MS analyses of the essential oil of Cinnamomum verum showed that different compounds such as cinnamaldehyde $(89.31 \%)$, cinnamyl acetate $(2.44 \%)$, linalool $(1.60 \%)$ consist the major portion of the oil $(93.35 \%)$. chemical ability of Cinnamomum verum essential oil was demonstrated by the existence of this three compounds, which exhibited antimicrobial activity.

\begin{tabular}{llllll}
\hline \multirow{2}{*}{ Essential oil or compound } & \multicolumn{1}{l}{ MIC $(\boldsymbol{\mu g} / \mathbf{m L})$} & & & \\
\cline { 2 - 6 } & E.coli & P. aeruginosa & S. aureus & C. albicans & A. Niger \\
\hline E.O of $\boldsymbol{C}$. Verum & $265.44 \pm 53.56$ & $335.34 \pm 68.06$ & $576.71 \pm 112.52$ & $231.37 \pm 51.03$ & $119.26 \pm 25.78$ \\
Tetracycline & $0.86 \pm 0.29$ & $0.94 \pm 0.31$ & $0.85 \pm 0.34$ & n.t & n.t \\
Pinicilin & $0.66 \pm 0.23$ & $0.87 \pm 0.37$ & $<0.05$ & n.t & n.t \\
Chloramphenicol & n.t & n.t & n.t & $<0.05$ & $0.75 \pm 0.22$ \\
Amphotericin B & n.t & n.t & n.t & $0.75 \pm 0.15$ & $3.13 \pm 1.06$
\end{tabular}

MIC, minimum inhibitory concentration, values given as $\mu \mathrm{g} / \mathrm{mL} \mathrm{Nt}$, not tested

Such results were observed in work by Didry et al., ${ }^{31}$ in which cinnamaldehyde with other three compounds: eugenol, thymol and carvacrol, also the synergistic effect with certain combinations of this compounds exhibit an inhibitory activity on oral microorganisms such as: Streptococcus sp., Peptostreptococcus sp. and Prevotella $s p$. Also the work of Chen et al., ${ }^{32}$ who showed inhibitory activity of cinnamaldehyde with Carvacrol and lauryl arginate against Salmonella Tennessee in intestinal infections. Many publications have reported the antimicrobial capacity of cinnamaldehyde-rich essential oils especially the same species of Cinnamomum $s p .^{33-40}$

\section{Conclusion}

Our work has given a cosmetic application marketed in the morocan market, hence the use of Cinnamomum verum essential oil for the treatment of mycoses. During this work we carried out a chemical analysis of this oil by GC-MS which confirmed the attendance of cinnamaldehyde as a major compounds, also present an added value in the pharmaceutical and cosmetic preparations according to their importance of the inhibition of several pathogenic bacteria and fungi. On the other hand, our results of antibacterial activities against three bacteria and two fungi (Escherichia coli, Pseudomonas aeruginosa, Staphylococcus aureus, Candida albicans and Aspergillus niger) have shown the effectiveness of this essential oil and the confirmation of several previous works, which explains the use of the essential oil Cinnamomum verum in cosmetic preparations, particularly the treatment of mycoses.

\section{Acknowledgments}

None.

\section{Conflicts of interest}

The author declares no conflicts of interest.

\section{References}

1. Nohynek GJ, Antignac E, Re T, et al. Safety assessment of personal care products/cosmetics and their ingredients. Toxico App Pharmaco.2010;243:239-259.

2. Antignac E, Nohynek GJ, Re T, et al. Safety of botanical ingredients in personal care products/cosmetics. Food Chem Toxico. 2011;49(2):324341 .

3. Safia B, Ahmed B, Rachid I, Optimization of The Formulation Parameters of A Para pharmaceutical 100\% Bio Cream. MATTER: Intern J Sci and Techn. 2017;4(3):104-112.

4. Petitot F, Moreels AM, Paquet F. Evolution of the percutaneous penetration and distribution of uranyl nitrate as a function of skin-barrier integrity: an in vitro assessment. Drug Chem Toxico. 2010;33:316-324.

5. Rosenbloom AL. Pediatric Endo-Cosmetology and the Evolution of Growth Diagnosis and Treatment. J pediatrics. 2011;158:187-193.

6. Rao JV, Pallela R, Prakash GVSB. Marine Cosm. Trends Prosp. 2011;20:77-103

7. Corvo J, Angulo J, Breugnot J, et al. 14th Inter Cong Stereology Image Analy. 2015. p. 1-3.

8. Vidale M, Salviulo G, Zorzi F, et al. J British Inst Persian Stud. 2016;54:1-24.

9. Gökçe EH,. Yapar EA, Tanrıverdi ST, et al. I Nanobiomat Galen Formu Cosm. 2016;10:363-393.

10. Kapuścińska I, Nowak I. Nanobiomat Galen Formu Cosm. 2016;10:395417.

11. Ainane T, Askaoui Z, Elkouali M, et al. Chemical composition and antibacterial activity of essential oil of Nigella sativaseeds from Beni Mellal (Morocco): What is the most important part, Essential Oil or the rest of seeds?. J Mater Environ Sci. 2014;5:2017-2020.

12. Ainane T, Elkouali M, Ainane A, et al. Moroccan traditional fragrance based essential oils: Preparation, composition and chemical identification. Der Pharma Chem. 2014;6:84-89. 
13. Talbi T, Ainane D, Boriky L, et al. Antibacterial activity of Eudesmanolide compounds isolated from medicinal plant Artemisia herba-alba. J Mater Environ Sci. 2015;6:2125-2128.

14. Maadane N, Merghoub T, Ainane H, et al. Antioxidant activity of some Moroccan marine microalgae: Pufa profiles, carotenoids and phenolic content. J biotech. 2015;215:13-19.

15. Talbi B, Saadali D, Boriky L, et al. Two natural compounds-a benzofuran and a phenylpropane-from Artemisia dracunculus. Asian nat Prod Res. 2016;18:724-729.

16. Maree J, Kamatou G, Gibbons S, et al. The application of GC-MS combined with chemometrics for the identification of antimicrobial compounds from selected commercial essential oils. Chemomet Intelli Lab Syst. 2014;130:172-181.

17. Ertas MA, Yilmaz M. LC-MS/MS and GC-MS analyses of three endemic Astragalus species from Anatolia towards their total phenolic-flavonoid contents and biological activities. Firat Nat Prod Res. 2015;29:529-534

18. Maadane N, Merghoub N, El Mernissi T, et al. Antimicrobial Activity of Marine Microalgae Isolated from Moroccan Coastlines. Microbio Biotech Food Sci. 2017;6:1257-1260.

19. Ainane T, Abourriche A, Kabbaj M, et al. Anti-platelet aggregation mechanisms of quercetin fatty acid ester. $J$ Chem Pharma Res. 2014;6:599-606.

20. Ainane T, Gharby S, Talbi M, et al. Moroccan Formulation of Oils for the Care of Hair: Chemical Composition and Antibacterial Activity. SOJ Biochem. 2016;2(2):1-8.

21. Park IK, Lee HS, Lee SG, et al. Insecticidal and Fumigant Activities of Cinnamomum cassia Bark-Derived Materials against Mechoris ursulus (Coleoptera: Attelabidae). Jagricult food chem. 2000;48(6):2528-2531.

22. Chericoni JM, Prieto P, Iacopini P, et al. In Vitro Activity of the Essential Oil of Cinnamomum zeylanicum and Eugenol in Peroxynitrite-Induced Oxidative Processes. J Agricult food chem. 2005;53:4762-4765.

23. Dighe VV, Gursale AA, Sane RT, et al. Quantitative Determination of Eugenol from Cinnamomum tamala Nees and Eberm. Leaf Powder and Polyherbal Formulation Using Reverse Phase Liquid Chromatography. Chromatographia. 2005;61(9):443-446.

24. Wang SY, Chen PF, Chang ST. Antifungal activities of essential oils and their constituents from indigenous cinnamon (Cinnamomum osmophloeum) leaves against wood decay fungi. Biores Techn. 2005;96:813-818.

25. Gursale V, Dighe G, Parekh. Simultaneous Quantitative Determination of Cinnamaldehyde and Methyl Eugenol From Stem Bark of Cinnamomum zeylanicum Blume Using RP-HPLC. J Chromat Sci. 2010;48:59-62.

26. Chang ST, Chen PF, Chang SC. Antibacterial activity of leaf essential oils and their constituents from Cinnamomum osmophloeum. $J$ Ethnopharmaco. 2001;77:123-127.

27. Park IK, Park JY, Kim KH, et al. Nematicidal activity of plan essential oils and components from garlic (Allium sativum) and cinnamon (Cinnamomum verum) oils against the pine wood nematode (Bursaphelenchus xylophilus). Nematology. 2005;7:767-774.

28. Bouhdid S, Abrini J, Amensour M, et al. Functional and ultrastructural changes in Pseudomonas aeruginosa and Staphylococcus aureus cells induced by Cinnamomum verum essential oil. $J$ Appl Microbio. 2010;109(4):1139-1149.

29. Gende LB, Floris I, Fritz R, et al. Bull Insect. 2008;61:1-4

30. Unlu M, Ergene E, Unlu GV, et al. Composition, antimicrobial activity and in vitro cytotoxicity of essential oil from Cinnamomum zeylanicum Blume (Lauraceae). Food Chem Toxico. 2010;48(11):3274-3280.

31. Didry N, Dubreuil L, Pinkas M. Activity of thymol, carvacrol, cinnamaldehyde and eugenol on oral bacteria. Pharma. Acta Helv. 1994;69:25-28.

32. Chen W, Golden DA, Critzer FJ, et al. Antimicrobial Activity of Cinnamaldehyde, Carvacrol, and Lauric Arginate against Salmonella Tennessee in a Glycerol-Sucrose Model and Peanut Paste at Different Fat Concentrations. J Food Prot. 2015;78:1488-1495.

33. Lin SSC, Lu TM, Chao PC, et al. In Vivo Cytokine Modulatory Effects of Cinnamaldehyde, the Major Constituent of Leaf Essential Oil from Cinnamomum osmophloeum Kaneh. Phyto Res. 2011;25(10):15111518 .

34. De Oliveira MMM, Brugnera DF, Do Nascimento JA, et al. Cinnamon essential oil and cinnamaldehyde in the control of bacterial biofilms formed on stainless steel surfaces. Europ Food Res Techno. 2012;234(5):821-832.

35. Li YQ, Kong DX, Wu H. Analysis and evaluation of essential oil components of cinnamon barks using GC-MS and FTIR spectroscopy. Indus Crops Prod. 2013;41:269-278.

36. Trinh NTT, Dumas E, Thanh ML, et al. Effect of a Vietnamese Cinnamomum cassia essential oil and its major component transcinnamaldehyde on the cell viability, membrane integrity, membrane fluidity, and proton motive force of Listeria innocua. $J$ Microbio. 2015;61(4):263-271

37. Chen YF, Wang YW, Huang WS, et al. Trans-Cinnamaldehyde, An Essential Oil in Cinnamon Powder, Ameliorates Cerebral IschemiaInduced Brain Injury via Inhibition of Neuroinflammation Through Attenuation of iNOS, COX-2 Expression and NFא-B Signaling Pathway. Neuromol Medic. 2016;18(3):322-333.

38. Wen $\mathrm{P}, \mathrm{Zhu} \mathrm{DH}, \mathrm{Wu} \mathrm{H}$, et al. Encapsulation of cinnamon essential oil in electrospun nanofibrous film for active food packaging. Food Cont. 2016;59:366-376.

39. Catalá AC, Ferrer MAB. Nereis: Revi Ibero Interdis Mét Mod Sim. 2017;9:13-24.

40. Kot K, Wierzchowska A, Grużewska D, et al. The effects of selected phytochemicals on biofilm formed by five methicillin-resistant Staphylococcus aureus. Nat Prod Res. 2017;32(11):1-4. 